\title{
O TERCEIRO DISCURSO DO FEDRO - UM DIVERTIMENTO SOBRE AS PAIXÕES?
}

\author{
THE THIRD SPEECH IN PLATO'S' PHAEDRO - A DIVERTISSEMENT ON MATTER OF PASSIONS?
}

Luiz Paulo Rouanet*

\section{RESUMO}

Neste texto procuraremos analisar o trecho que se estende de 244 a até $257 \mathrm{~b}$, que contém o terceiro discurso do Fedro. O primeiro é atribuído a Lísias (231 a - 234 c); o segundo, pronunciado por Sócrates, é depois por ele rejeitado - ele o teria pronunciado sob a influência de Eros, e o atribui a Fedro (237 a - 241 c). A intenção, aqui, é nos concentrarmos no terceiro discurso, a fim de precisar o seu caráter sério, no sentido filosófico do termo ou, então, um caráter de brincadeira ou jogo empreendido por Sócrates/Platão. Em princípio, partiremos da hipótese de que sim, trata-se de um discurso com intenção séria, ainda que vazado em forma retórica, e adequado ao momento de distensão que Sócrates vive com seu interlocutor, Fedro. Analisaremos, então, o conteúdo do discurso, que versa sobre a alma, efetuando uma definição desta e efetuando uma classificação dos tipos de alma. O trecho pode ser aproximado de passagens do Fédon e da famosa Carta VII. O método empreendido é a análise textual, com auxílio eventual de comentadores.

PALAVRAS-CHAVE: Platão. Paixões. Retórica. Alma.

\begin{abstract}
In this paper we will analyse the passage which goes from $244 \mathrm{a}$ to $257 \mathrm{~b}$, which contains the third speech of Plato's Phaedro. The first speech is attributed to Lisias (231 a - $234 \mathrm{c})$; the second speech, pronounced by Socrates, is lately rejected - the speech would be proffered under the influence of Eros, and Socrates attributed its authorship to Phaedro (237 a - 241 c). Our goal, here, is to concentrate in the third speech, with the finality of assert its seriousness, in the philosophical meaning of the word, or else, to show its character of divertissement or play by Socrates/Plato. In principle, we will assume the hypothesis that it is a speech with a serious intent, notwithstanding its rhetorical form, fitted to the moment of distension which Socrates has with his partner, Phaedro. We will analyse, then, the content of the speech, which is about the soul, by means of a definition of this last and a classification of the kinds of souls. The passage can be compared to passages of the Phaedon and of the famous Letter VII. The method here adopted is the textual analysis, with the help of some interpreters.
\end{abstract}

KEYWORDS: Plato. Passions. Rhetoric. Soul.

\footnotetext{
* Doutor em Filosofia, professor na UFSJ e UFMG. E-mail: luizpaulorouanet@gmail.com.
} 
[...] a beleza era muito fácil de ver por causa do brilho peculiar, quando, no séquito de Zeus, tomando parte no coro dos bem-aventurados e os demais no de outra divindade, gozávamos do espetáculo dessa visão admirável e, iniciados nesse mistério que, com toda a justiça, pode ser denominado sacratíssimo, e que celebrávamos na plenitude da perfeição e livres dos males que nos alcançam no futuro, fomos admitidos a contemplar sob a luz mais pura aparições perfeitas, simples, imutáveis, puros também e libertos deste cárcere de morte que com o nome de corpo carregamos conosco e no qual estamos aprisionados como a ostra em sua casca. (Ph., 250b-250c).

\section{O TERCEIRO DISCURSO (244 A - 257 B)}

Nesta apresentação, irei me concentrar no trecho situado entre 244 a e 257 b. Trata-se do terceiro discurso pronunciado no Fedro, os primeiros tendo sido de Lísias, lido por Fedro, o segundo de Sócrates, mas atribuído a Fedro e o terceiro de Sócrates, atribuído a "Estesícoro, filho de Eufemo, o piedoso, natural de Hímera, a cidade dos anelos" (244 a). Ignoro o motivo de semelhante atribuição, provavelmente inspirada na prática dos oradores, e possivelmente com intenção jocosa. Talvez a atribuição a terceiros seja justamente para permitir um pouco mais de liberdade na exposição, com utilização de elementos retóricos. De qualquer modo, esse discurso tem supostamente intenção séria, e Sócrates o pronuncia de rosto descoberto, diferentemente do que fizera ao pronunciar seu primeiro discurso. "Hímera, a cidade dos anelos". Pode tratar-se de indicação de que o amor de Sócrates, agora, está apenas no plano intelectual, no dos desejos, não no das realizações. O discurso anterior fora atribuído a "Fedro, filho de Pítocles, o homem vão, natural de Mírrina, a cidade da mirra e da volúpia" (244a). Passa-se assim do plano do amor carnal e realizado para o plano do amor intelectual. ${ }^{2}$

Sócrates passa então a elogiar o delírio, e o estado de loucura: "a verdade é que os maiores bens nos vêm do delírio, que é, sem a menor dúvida, uma dádiva dos deuses" (244 a). Estranha asserção por parte de quem, pelo menos segundo a tradição aceita, valoriza sempre a razão e a parte superior da alma. Em todo caso, elogia as sacerdotisas (e Diotima não era uma profetista de Delfos?):

A profetisa de Delfos e as sacerdotisas de Dodona, em seus delírios, prestaram inestimáveis serviços à Hélade, tanto nos negócios públicos como nos particulares; ao passo que no juízo perfeito pouco fizeram, ou mesmo nada. Se mencionássemos a Sibila e todos os que, por inspiração divina, com suas predições endireitaram a vida

\footnotetext{
1 "Sóc.: Sabes o que vou fazer? Fed.: Não compreendo. Sóc.: Tapar o rosto, para chegar depressa ao fim do discurso e não me atrapalhar de vergonha, quando olhar para o teu lado.” (237 a).

${ }^{2}$ Ver a respeito em Benoit (2017, p. 100-101, passim).
} 
de tanta gente, alongaríamos sem necessidade o discurso com coisas muito conhecidas. (244 a-b).

Em seguida, relaciona manikê, mania, com mantikê, arte divinatória. Efetua toda uma análise filológica do termo. Em terceiro lugar, vem o delírio próprio às Musas e à poesia, em particular. Defende a combinação, naquele que deseja ser poeta, da técnica e da inspiração pelas Musas:

[...] quem se apresenta às portas da poesia sem estar atacado do delírio das Musas, convencido de que apenas com o auxílio da técnica chegará a ser poeta de valor, revela-se, só por isso, de natureza espúria, vindo a eclipsar-se sua poesia, a do indivíduo equilibrado, pela do poeta tomado do delírio. (245 a).

Sócrates se propõe a demonstrar, nesse discurso, que o amor tem a ver com o delírio, e que este foi inspirado pelos deuses, logo, que o amor é inspirado pelos deuses. Assim, visa demonstrar que "essa espécie de delírio nos foi dada pelos deuses para nossa maior felicidade" (245 c). Desse modo, é preciso conhecer a alma, lugar onde se manifesta essa afecção: "O ponto está, inicialmente, em alcançar a verdade a respeito da natureza da alma, assim divina como humana, pela observação de seus atos e afecções” (245a).

A passagem que se estende de 245 c a 247 c do Fedro pode ser aproximada do Fédon, e o faremos no momento oportuno. Mas sigamos passo a passo o primeiro texto.

Aqui, já se inicia pela afirmação, parte-se do seguinte princípio: "A alma toda é

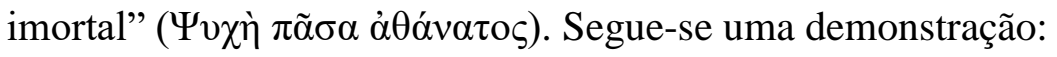

\footnotetext{
o que move a si mesmo é imortal; porém, o que movimenta outra coisa ou é movido por outra coisa deixa de viver quando cessa o movimento. Somente o ser que a si mesmo se movimenta, pelo fato de nunca abandonar-se, é que não para de mover-se, como é fonte e princípio de movimento para tudo o que recebe movimento de fora. Só o princípio não é gerado. (245 c).
}

Trata-se de uma demonstração dedutiva, como se pode perceber, diferentemente do que ocorre no Fédon, quando se parte dos argumentos até chegar à afirmação de que a alma é imortal (Fédon, 107 a, passim): “a alma, portanto, Cebes, é mais do que tudo coisa imortal e indestrutível e, realmente, nossas almas existirão no Hades”. Aproximadamente nos mesmos termos, mas na forma de uma demonstração cabal, é o que afirma Sócrates no Fedro. Assim, do princípio 
necessariamente é que se origina tudo o que nasce, ao passo que ele mesmo não provém de nada, pois se se originasse de alguma coisa, não seria princípio. Ora, uma vez que nunca nasceu, terá também de ser indestrutível, pois se o princípio viesse a perecer, nem ele poderia renascer de alguma coisa, nem nada teria nascimento nele, a ser verdade que tudo terá de provir de algum princípio. [...] Demonstrada, assim, a imortalidade do que se movimenta por si mesmo, não terá que envergonhar-se quem afirmar que nisso consiste a essência e a própria ideia da alma. (245 d- e).

E Sócrates conclui o raciocínio: “Ora, se as coisas se passam, realmente, desse modo, se a alma é o que a si mesmo se movimenta, necessariamente a alma não pode ser gerada e é imortal." (245 e- 246 a).

A alma é imortal, portanto. Quanto à sua natureza, Sócrates prossegue, iniciando a analogia com uma parelha de cavalos, uma vez admitida a dificuldade, se não impossibilidade de versá-lo em "linguajar humano". Desse modo, a alma "assemelha-se a uma força natural composta de uma parelha de cavalos alados e de seu cocheiro" (246 a - b). As parelhas são desiguais de acordo com a qualidade daqueles que os possuem, se são deuses, filósofos, poetas, sofistas et alii (a relação completa aparece em $248 \mathrm{~d}-\mathrm{e}$ ). Sempre aquele cavalo que possui alma puxa aquele que se inclina mais para as paixões corporais: "Sempre é uma alma que dirige o que não tem alma e, percorrendo a totalidade do universo, assume formas diferentes" (246 b). Quando se trata, portanto, de uma composição mista, trata-se de um animal, e é mortal. Já a imortal só compete aos deuses e "não pode ser compreendida racionalmente" (246 c).

As asas tendem a levar para cima, para o que é imortal. Assim descreve Platão o cortejo dos deuses, em passagem que nos faz pensar em Hesíodo (Teogonia) e no poema de Parmênides: “A virtude natural da asa consiste em levar o que é pesado para as alturas onde habita a geração dos deuses, sendo ela, de tudo o que se relaciona com o corpo, o que em mais alto grau participa do divino" (246 d). E prossegue:

\footnotetext{
Ora, o divino é belo, sábio, bom e tudo o mais do mesmo gênero, sendo isso o que alimenta e faz crescer as asas da alma; ao passo que o feio, o mal e tudo o mais que se opõe àquelas qualidades a fazem murchar e perecer. Zeus, o guia supremo, abre a marcha no céu com o seu carro alado, ordenando tudo e de tudo cuidando, seguido por um exército de deuses e demônios, repartidos em onze grupos. Só fica Héstia na morada dos deuses; os demais, que compõem o número dos doze deuses dominadores, seguem à frente do grupo para que foram designados. (246 d - $247 \mathrm{a}$ ).
}

Enquanto as parelhas das almas mortais lutam entre si, e ora arrastam o carro e seu condutor para a terra, ora para o céu, de maneira desequilibrada. Já as parelhas dos deuses, "por serem equilibradas e de fácil direção, sobem depressa" (247 b). Não é de estranhar que 
Sócrates, no início desse discurso, tenha louvado o delírio das Musas, uma vez que foi necessária certa dose de loucura - no bom sentido, manía - para conceber esse relato. Eis como descreve a chegada das carruagens dos imortais:

\begin{abstract}
As almas denominadas imortais, uma vez alcançado o vértice, passam para o outro lado e se postam, assim, no dorso da abóbada celeste, e, uma vez ali chegadas, a revolução do céu as arrasta no seu curso, contemplando elas as realidades que se encontram além do céu. (247 b- c).
\end{abstract}

Haverá aí uma analogia entre os deuses, doze no total, e os astros celestes? Podemos conjecturar.

Sócrates prossegue retratando o céu, como se lá houvesse estado, ou como se o tivesse contemplado, e o diz como verdade - aqui, novamente, a analogia com o poema de Parmênides se impõe: "é preciso ter-se coragem de dizer a verdade, máxime quando se fala da

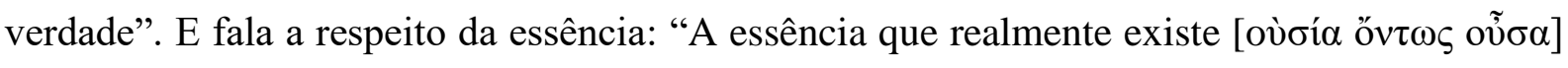
e é sem cor e sem forma, impalpável e só pode ser percebida pelo guia da alma, o intelecto, sobre ser o objeto do verdadeiro conhecimento, tem aqui a sua sede" (247 c).

Somente assim, no estado de delírio profético, pode Sócrates falar a respeito da essência do que realmente existe, algo que Platão, na Carta VII (apócrifa, no entanto), considera impossível para um simples mortal. Somente ali, em todo caso, seria possível, para a alma que ali chegasse, contemplar as essências verdadeiras. Somente o "pensamento de

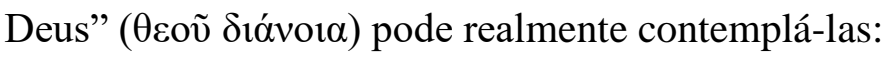

\footnotetext{
Ora, o pensamento de Deus, nutrido exclusivamente de inteligência e de conhecimento puro, tal como se dá, aliás, com toda alma que se preocupa de receber o conhecimento que lhe convém, alegra-se quando chega o tempo de voltar a perceber a realidade e se nutre com delícias da contemplação da verdade, até que o movimento circular a traga de novo para o ponto de partida. $(247 \mathrm{~d})$.
}

Deus, então, ou a alma que se alimenta do conhecimento, contempla as ideias:

No decurso dessa revolução contempla a justiça em si mesma, contempla a temperança, contempla o conhecimento, porém não o conhecimento passível de crescimento e que difere de acordo com o objeto com que se relaciona e a que em nossa curta existência damos a denominação de seres, mas o conhecimento do que verdadeiramente existe. $(247 \mathrm{~d}-\mathrm{e})$.

Mas isso só é dado aos deuses, aos imortais. Quanto aos demais, alguns se aproximam mais, outros menos dessas realidades, mas nenhum consegue fixá-las por muito tempo. 
Das outras almas, dos homens, a que melhor se esforça por acompanhar os deuses e com eles parecer-se, eleva a cabeça do cocheiro para o outro lado do céu e se deixa arrastar pelo movimento circular; porém, perturbada pelos cavalos, mal pode contemplar as essências. A segunda melhor ora se ergue ora se abaixa, mas sempre atarefada com os cavalos, percebe umas tantas essências e deixa passar outras. As demais almas também desejam ardentemente alcançar a parte superior e se afanam nesse sentido; porém, não sendo suficientemente fortes, caem para a parte inferior da abóbada, amontoam-se, machucam-se, procurando cada uma passar à frente de sua vizinha. A confusão é enorme... (248 a-b).

Qual melhor retrato de nossa humana condição? Ora nos aproximamos, ou acreditamos nos aproximar da verdade, e da essência das coisas, ora caímos no burburinho, na azáfama cotidiana, esquecendo nossos anseios anteriores. Ora acreditamos que podemos chegar ao ápice, ora desesperamos disso e nos contentamos com uma vida na hybris... Consciências infelizes, diria Hegel mais tarde. Prossegue Platão, de maneira implacável:

Depois desse trabalho insano, todas voltam sem terem conseguido contemplar a realidade e, uma vez dali afastadas, alimentam-se apenas com a opinião. A razão de tamanho empenho de contemplar a Planície da Verdade está no fato de nascer justamente naquele prado o alimento adequado para a porção mais nobre da alma e de nutrir-se com isso a natureza das asas que confere à alma mais leveza. (248 b c).

Em linguagem que sugere mistérios e fórmulas secretas, diz Sócrates ainda:

A lei de Adrasteia é a seguinte: toda alma que, no séquito de algum deus, consegue contemplar algo das verdadeiras realidades, fica livre de padecimentos até à revolução seguinte, e se sempre conseguir isso mesmo, nunca mais virá a sofrer coisa nenhuma. (248 c).

Novamente, aqui, a referência é o Fédon, e o reino dos bem-aventurados, daquelas almas que, tendo se dedicado por várias gerações à contemplação da verdade, não precisam mais retornar ao ciclo mortal e terreno, podendo permanecer para sempre naquela região supraceleste.

Mas, certamente, aqueles que se considera que viveram uma vida excepcionalmente pia, estes ficam livres, arrancados desses lugares subterrâneos como a uma prisão, eles chegam lá em cima, numa estadia pura, e se estabelecem na superfície da Terra. Entre eles, aqueles que conseguiram se purificar tanto quanto preciso graças à filosofia vivem, para todo o tempo futuro, absolutamente sem corpos; atingem moradas ainda mais belas, que não é fácil descrever. (Fédon, $114 \mathrm{~b}-\mathrm{c}$ ). 
Retornando ao Fedro, segue-se a classificação dos tipos de alma, de acordo com a posição nessa escala que vai do mais próximo para o mais distante das realidades, das essências, e pela maneira como voltarão a encarnar-se. Em primeiro lugar, vem aquela que, não conseguindo manter-se nas alturas, tornando-se pesada, "perde as asas e cai no chão" (248 c). Não pode voltar no corpo de um animal, e aquela "que teve uma visão mais rica penetre no germe de um homem destinado a ser amigo da sabedoria e da beleza ou cultor das Musas e do amor" (248 d). Vêm em seguida um "rei legítimo, potentado ou guerreiro de prol"; em terceiro lugar, um "político, ecônomo ou comerciante"; em quarto lugar, "um ginasta amigo dos exercícios físicos ou alguém entendido na cura das doenças do corpo"; em quinto, "terá vida de adivinho ou de iniciado nos mistérios; em sexto (248 e), “será poeta ou alguém afeito às artes da imitação"; em sétimo, "artista ou lavrador"; em oitavo, "sofista ou demagogo" e em último, "algum tirano".

Não deixa de ser curiosa essa lista, que nos dá ideia da importância relativa das diversas atividades para Platão. O sofista ou demagogo só entram em penúltimo lugar, antes dos tiranos! $!^{3}$ Nos três primeiros lugares estão 1. sábio; 2. o rei, potentado ou guerreiro, e 3. o político, o economista e o comerciante. Estas são as funções "úteis" ao Estado. A visão é compatível com aquela defendida na República, notadamente.

Segue-se uma descrição do destino das almas, dos ciclos de encarnação e reencarnação. O que deve nos reter aqui é a sugestão de um sistema que, certamente, inspirará a concepção cristã tripartite do Inferno, Purgatório e Céu. Haveria um julgamento, após o qual

umas tantas [almas[ descem para prisões correcionais embaixo da terra, a fim de cumprirem a pena cominada, enquanto outras, aligeiradas pela sentença, são conduzidas para determinado lugar do céu, onde levam uma vida mais digna do que a anteriormente vivia sob a forma humana. (249 a). ${ }^{4}$

Segue-se agora passagem significativa, na qual Platão reafirma sua teoria da reminiscência, bem como a teoria das ideias, talvez a passagem central do discurso que ora examinamos:

[...] a condição humana implica a faculdade de compreender o que denominamos ideia, isto é, ser capaz de partir da multiplicidade de sensações para alcançar a unidade mediante a reflexão. É a reminiscência do que nossa alma viu quando andava na companhia da divindade, desdenhando tudo a que atribuímos realidade na presente existência alçava a vista para o verdadeiro ser. Daí justificar-se só ter asas o

\footnotetext{
${ }^{3}$ Para um estudo recente e completo sobre a relação de Platão com os sofistas, ver Vidal (2016).

${ }^{4}$ Ver Le Goff (2017, p. 39 et seq.).
} 
pensamento do filósofo, pois este se aplica com todo o empenho, por meio da reminiscência, às coisas que asseguram ao próprio deus a sua divindade. Só atinge a perfeição o indivíduo que sabe valer-se da reminiscência e foi devidamente iniciado nos mistérios. (249 c).

Em primeiro lugar, chama a atenção o caminho, que vai do sensível para o inteligível, contrariamente ao que habitualmente se afirma ou pensa a respeito da teoria do conhecimento de Platão: "a condição humana implica a faculdade de compreender o que denominamos ideia, isto é, ser capaz de partir da multiplicidade de sensações para alcançar a unidade mediante a reflexão". Então, o caminho do conhecimento parte do múltiplo para o uno. Neste ponto, portanto, a teoria do conhecimento de Platão não diferiria tanto daquela de Aristóteles, embora haja muito mais aspectos a serem considerados no que diz respeito a essa relação, o que foge de nosso presente escopo.

O segundo ponto a destacar é o caráter iniciático desse percurso: "Só atinge a perfeição o indivíduo que sabe valer-se da reminiscência e foi devidamente iniciado nos mistérios". Na Carta VII, novamente, encontramos referência aos "mistérios": mistérios de Elêusis, ou de algum outro culto, ou dos mistérios da própria filosofia? Creio que jamais saberemos, pois, justamente, não era possível falar a respeito dos mistérios, sob risco de sacrilégio, punível com a morte. Essa era acusação que pesava sobre Alcibíades, e sobre todo o episódio do Banquete (STRAUSS, 2001).

Esta forma de delírio, a quarta, é a paixão pela beleza: “O indivíduo atacado de semelhante delírio, sempre que apaixonado das coisas belas, é denominado amante" (249 e). Todas as almas humanas já contemplaram pelo menos uma vez essa realidade, pois senão não teriam forma humana, mas alguns a esquecem rapidamente, enquanto outras, bem poucas, lembram-se delas: "são bem poucas as que conservam a lembrança do que viram" (250 a).

Em seguida, em passagem admirável, na qual Sócrates, esquecendo-se de si mesmo, dá a entender que faz parte daquelas almas que contemplaram e retiveram aquilo que viram:

[...] a beleza era muito fácil de ver por causa do brilho peculiar, quando, no séquito de Zeus, tomando parte no coro dos bem-aventurados e os demais no de outra divindade, gozávamos do espetáculo dessa visão admirável e, iniciados nesse mistério que, com toda a justiça, pode ser denominado sacratíssimo, e que celebrávamos na plenitude da perfeição e livres dos males que nos alcançam no futuro, fomos admitidos a contemplar sob a luz mais pura aparições perfeitas, simples, imutáveis, puros também e libertos deste cárcere de morte que com o nome de corpo carregamos conosco e no qual estamos aprisionados como a ostra em sua casca. $(250 \mathrm{~b}-\mathrm{c})$. 
Caindo em si que, de certa maneira se deixara levar e até mesmo revelara parte dos mistérios, afirma: "Basta de recordações; a pungente saudade do passado levou-nos a esses devaneios" (250 c). Aponta o órgão privilegiado para a contemplação dessa realidade, a Beleza, na terra, a saber, a vista (250 d). Passa a descrever as sensações que a contemplação da beleza provoca naqueles que a contemplam, conforme sejam mais ou menos preparados para essa visão. Não nos deteremos sobre essa parte, que se estende de 251 c a 253 a, por nos ocupar demasiado tempo nesta exposição, e não ser tão relevante para nossos propósitos. A partir de 253 d, Sócrates retorna à analogia do cocheiro e dos cavalos. Demora-se mostrando como os cavalos diferem entre si, e como o cocheiro faz para refreá-los.

Implícita em toda essa descrição, é preciso dizer, está o amor homossexual, mais precisamente, o amor entre o mais velho e o menino ou adolescente (p. ex., 256 a). O caráter homossexual dessa relação fica claro, por exemplo, quando afirma Sócrates:

Sim, ele também [o amado] ama, porém não sabe a quem ama e é incapaz de explicar o que se passa; como quem apanhou oftalmia de outra pessoa, não sabe dar a razão do seu padecimento, por não perceber que ela se vê no seu amante como num espelho [...]. (255 d, grifos nossos).

Esse caráter espelhado da relação fala por si só: procura-se no outro o si mesmo.

No entanto, quando esse desejo é sublimado, e não realizado, encaminham-se ambos para a filosofia:

\footnotetext{
Se prevalecem os elementos mais nobres da alma, que dirigem o entendimento para uma vida ordeira e dedicada à filosofia, passam ambos a desfrutar aqui mesmo uma vida feliz e harmoniosa, por serem de conduta ilibada e saberem dominar-se, pois escravizam a porção geratriz do vício e libertam a que dá nascimento à virtude. (256 $\mathrm{a}-\mathrm{b})$.
}

A satisfação do desejo, porém, é considerada vulgar. Isso ocorre quando os cocheiros se descuidam e os cavalos tomam os freios nos dentes, "decidindo-se pelo que o vulgo considera felicidade máxima: a satisfação de seus desejos" (256 c).

E assim encerra Sócrates seu segundo discurso, reconhecendo seu caráter poético e mesmo arrebatado, mas que se pretende merecedor, pela beleza, do deus ao qual é dedicado, Eros:

Seja esta, meu querido Eros, a melhor e mais bela palinódia que eu te poderia oferecer para expiar minha falta. Se sob todos os aspectos, mas principalmente quanto ao vocabulário, atingi as raias da poesia, foi porque Fedro me obrigou a 
assim falar. Perdoa meu primeiro discurso e aceita este outro em seu lugar. Sê-me favorável e propício, e na tua cólera não me prives do conhecimento da arte de amar que me concedeste, nem o diminuas em nada. Ao contrário: dá que junto dos moços cresça mais, ainda, o meu prestígio. (257 a).

\section{CONCLUSÃO}

Não resta dúvida, ao final desta exposição, que não obstante o caráter retórico e poético do segundo discurso pronunciado por Sócrates, este possui conteúdo sério, consistente com passagens de outros diálogos de Platão (Fédon, República) e com a Carta VII (cuja autenticidade, sempre é importante lembrar, não pôde ser comprovada, sendo por este motivo considerada apócrifa no sentido literal do termo).

Desse modo, as passagens sobre a alma, sobre a contemplação das Ideias (Verdade, Justiça Beleza etc.), sobre a teoria da reminiscência, sobre o caráter erótico do processo do conhecimento (cf. Banquete) são compatíveis com o que diz Platão em outros livros, levandonos a considerar o Fedro obra de intenção séria, por trás da aparência de brincadeira, ou divertimento, ao qual aludimos no título.

Divertimento sim, por que não, desde que voltado para o objetivo de atrair para a filosofia. Não por acaso, ao final do trecho examinado, Sócrates conclama Lísias a se dedicar à filosofia: "Obriga-o a parar com tais lucubrações e a voltar-se para a filosofia" (257 b). É preciso despertar no ouvinte, e no leitor, o desejo pela filosofia. E esse objetivo cumpre também, o final do diálogo, que culmina com a seguinte exortação, que não nos furtaremos a citar, e com a qual concluímos nosso próprio texto:

Querido Pã, e vós todas, divindades locais: dai-me alcançar a beleza interna, e que tudo o que eu tenho no exterior fique em consonância com o que trago dentro de mim; que o sábio me pareça sempre rico e seja todo o meu ouro o que apenas o homem temperante necessite e possa carregar. (279 c).

\section{REFERÊNCIAS}

BENOIT, H. A Odisseia de Platão. As aventuras e desventuras da dialética. São Paulo: Annablume, 2017.

LE GOFF, J. O nascimento do purgatório. Tradução Maria Idalina F. Lopes. Petrópolis: Vozes, 2017.

PLATÃO. Fedro. Tradução Carlos A. Nunes. Ed. bilíngue. 3. ed. Belém, PA: ed. UFPA, 2011. 
PLATON, Oeuvres complètes. Org. Luc Brisson. Paris: Flammarion, 2011.

VIDAL, G. R. La invención de los sofistas. México: Universidad Autónoma de México, 2016.

STRAUSS, L. On Plato's Symposium. Chicago: University of Chicago Press, 2001. 